\title{
Distribution of Local Expenditure for Sustainable Development of United Territorial Communities (economic and mathematical approach)
}

\author{
Lidiia Horoshkova* \\ Department of business, management \\ organizations and logistics \\ Zaporizhzhia National University \\ Zaporizhzhia, Ukraine \\ http://orcid.org/0000-0002-7142-4308
}

\author{
Ievgen Khlobystov \\ Department of ecology \\ National University of «Kyiv-Mohyla \\ academy» \\ Kyiv, Ukraine \\ http://orcid.org/0000-0002-9983-9062 \\ Damir Bikulov \\ Department of business administration \\ and international management \\ Zaporizhzhia National University \\ Zaporizhzhia, Ukraine \\ http://orcid.org/0000-0001-9188-7310
}

\author{
Liliya Filipishyna \\ Innovation Centre \\ Pervomaisk Branch of the \\ National University of Shipbuilding \\ named after Admiral Makarov \\ Pervomaisk, Ukraine \\ http://orcid.org/0000-0001-9552-1367
}

\begin{abstract}
The paper analyzes current expenditure system of united territorial communities, which includes funding of education, culture, health care, social safety net, housing and community amenities, infrastructure development, which together ensure territories' sustainable development. It has been proved that the current system of local finances management does not support their sustainable development and does not introduce viable mechanisms for the effective expenditure distribution inside united territorial communities (UTCs) between the settlements within them. The following arguments have been shown: UTCs include settlements characterized by different population size and income per capita. Due to migration processes the population size is unstable. The model of expenditure distribution between settlements of UTCs for provision of public goods using a system of linear homogeneous difference equations, taking into account national economy specifics has been proposed based upon foreign experience. It has been proposed to calculate the population size at certain time intervals, taking into account the expected (planned) changes of each settlement ${ }^{\prime} s$ population within UTCs and to distribute programmed expenditure for providing public goods within territories' sustainable development capacity.
\end{abstract}

Keywords—united territorial community, budget expenditure, public goods, population size, migration

I. STATEMENT OF THE PROBLEM IN GENERAL WAY AND ITS RELATION TO IMPORTANT SCIENTIFIC OR PRACTICAL TASKS

Transformation of the administrative and territorial system of Ukraine is one of the reform components that Ukrainian society badly needs. One of the ten priorities of the "Ukraine - 2020" Strategy for Sustainable Development" [1] approved by the Presidential Decree is decentralization and state socio-economic system reform, restructuring of the business entities territorial organization. Therefore, Ukraine and its economy need urgent scientific substantiation and practical implementation of measures aimed at sustainable geospatial development of the country amid transformation of its administrative territorial structure. Building a system of integrated, multi-criteria management of natural and economic systems, which include united territorial communities (UTCs), which will ensure regional and national sustainable development over the long term, remains a national problem. National sustainable development can only be ensured if UTCs organized because of decentralization are self-sufficient and financially viable. Thus, the UTCs face the following tasks: first, to form the revenue part of their budget more effectively; secondly, to move to self-sufficiency and rational resource and expenditure planning, which in the future will make territorial communities economically selfsufficient and financially viable. That is why, in the context of decentralization, the problem of the effective system of territorial communities` finances management building becomes especially relevant.

\section{ANALYSIS OF RECENT STUDIES AND PUBLICATIONS THAT HAVE INITIATED PROBLEM SOLUTION, WHICH THE AUTHOR REFERS ON}

Analysis of foreign decentralization experience has been conducted in the works of Wollmann H. (Denmark), Andre C., Garcia C. (Finland), Baldershrim H., Kulesza M. (Poland), Feltensteina A., Iwata S. (China) and others. [2-4]. Jourmard I., Giomo C., E., Salachna J. [5] studied models of local self-government, mechanism of local budgets` formation and models decentralized budgeting in European countries. Ukrainian scholars like Batalov O.A., Datsko O.I., Marunyak E.A., Lisovsky S.A., Murkovich L.L.., Oliynyk D.I., Oliynyk Y.B., Pavlyuk A.P., Rudenko L.G., etc. [6-11] dealt with current aspects of territorial communities' and local self-government's development problem solving.

\section{HIGHLIGHTING UNRESOLVED ISSUES TO WHICH THE ARTICLE IS DEVOTED}

The decentralization reform was launched in 2015. Appropriate legal framework was formed prior to its beginning, namely, amendments to the Tax Code of Ukraine and the Budget Code of Ukraine were adopted, which significantly expanded local self-government's financial capacity. 
The Article 143 of the Constitution of Ukraine contains a list of powers of a territorial community as a primary subject of local self-government, applied directly or through the local self-government bodies established by them. Local self-government bodies may be empowered by the law with particular powers of executive authorities. The state funds these powers`application in full at the expense of the State Budget of Ukraine or by allocating specific national taxes to the local budget according to the procedure stated by the law, and transfers related state property to local selfgovernment. However, our research has shown that along with the revenue expansion of local budgets, expenditure redistribution has taken place. Hence, there is a need to find an effective model for managing the UTCs expenditure.

\section{ARTICLE OBJECTIVES}

The main task of the study is to simulate the system for UTCs expenditure distribution management among settlements that comprise them, in order to create the mechanism that will ensure social justice and harmonious development.

\section{THE MAIN MATERIAL OF THE RESEARCH WITH JUSTIFICATION OF FINDINGS}

The effectiveness of the reform process can be achieved only if viable communities are being formed. According to "The methodology of viable communities Formation" [12], viable territorial communities are the territorial communities of villages (settlements, cities) that, through voluntary association, are able to provide, on their own or through appropriate local governments, a proper level of service provision, in particular in the field of education, culture, health, social safety net, housing and community amenities, taking into account the human resources, financial support and infrastructure development of a particular administrative and territorial unit. The list of UTCs basic expenditure is set out in Art. 89 of the Budget Code of Ukraine.

These regulatory instruments contain the list of UTCs main expenditures as a whole, but do not take into account that the communities include separate settlements. Our analysis reveals that there is no effective guarantee of optimal, balanced budget distribution between settlements UTC members in the regulatory framework for united territorial communities. This problem mostly arises in UTCs, which include settlements with different population size and per capita income levels.

As UTC's single council is formed by equal and direct elections, the number of representatives of each settlement depends on its population. That is, settlements where UTCs are formed may have decision-making advantages over settlements with smaller population size.

The second problem concerns the level of income per capita as it does not always depend on settlement's population size. The key determinant is the availability of natural resources, valuable land or a big profitable enterprise. It can also lead to uneven funds application, in particular for the settlements`development.

The third issue concerns fair, balanced expenditure and subvention distribution, which is possible if there is reliable information on the number of residents in UTC's settlements. There is almost no information of the kind, since the UTC formation is preceded by the elections announced by the Central Election Commission (CEC), based on information about residents' official domicile in settlements. There is some evidence that the domicile does not always coincide with the place of residence. In addition, there is a pendulum migration in the job search process between settlements. That is, there are those who go to work to another settlement every morning and return in the evening. There are those who go to work for a week, there are also seasonal jobs. Thus, the number of settlements` residents fluctuates. In this case, the traditional approach to distribution of necessary expenditure between settlements is not effective because it is based on the domicile of such agents without taking into account temporary migration. In turn, it is necessary to provide adequate settlement infrastructure, which absorb additional workforce in the morning (transport, public catering facilities, etc.). Transport infrastructure between communities`settlements also needs additional attention.

We consider that there is another issue concerning inefficiency of UTCs budget expenditure distribution to settlements - consideration of emigration, above all - labor migration abroad. Regions characterized by significant external labor migration (emigration) often have difference between their real population size and number taken into account by the CEC in the process of UTCs formation. This is also not possible to consider due to the current system of expenditure and other financial resources (subvention) distribution.

Therefore, there is a need to build mechanism for UTCs budget fair distribution.

Experience to solve this problem already exists. Thus, there is a principle of harmonious development in the EU, enshrined in the Treaty on the Functioning of the EU. It addresses the greater part of budget's expenditure distribution to less developed territories. This approach, in our opinion, threatens to integrate UTCs into such settlements, or to create communities that would prefer a subsidized development path instead of creating environment for their own financial capacity.

Another approach of economic liberalism is its opposite. It means dependence of budget expenditure on each participant's contribution. The USA have negative experience resulted from the approach. Threat to social equity caused disintegration of a significant number of municipalities from the rest of the territory, together with the richest areas and, consequently, their revenues, and left a gap in the total expenditure funding. However, this approach will encourage communities to seek new opportunities to earn money.

That is why it is advisable to provide individual approach in the formation of budget expenditure, taking into account peculiarities, based on the principles of social equity for UTC residents.

First, there is expenditures differentiation according to multi-criteria principle regarding financing of housing and community amenities related to public and mixed goods. Such services include, for example, road maintenance, transportation, amenity planting, street lighting.

Housing and community amenities are values, since they 
are goods, services, social and economic environment that satisfy person's needs or which a person consumes or applies.

Most often, goods are divided into private, public and mixed. Private goods are characterized by the fact that access to their consumption requires certain cost; their owners can exercise property rights; they are reproduced according to need; it is obligatory to receive benefits, i.e. they are rivalrous and excludable. The peculiarity of public goods is that they become available to all individuals (nonexcludable) without additional cost (non-rivalrous), and their owners cannot exercise property rights. Their main properties are as follows: non-rivalry - good's property which consumption does not diminish its quantity available for consumption by others; non-excludability - inability to limit consumption by all agents; indivisibility of consumption - the inability to consume parts of good. Mixed goods are goods that have private and public goods properties.

The peculiarity of public goods is that the consumer benefits from their consumption, whether he pays for them or not. State provides funding of the process of off-site improvements' services production, which is a consequence of their non-excludability. If private entrepreneurs offer these goods to buyers, most consumers would refuse to pay for them (there is no point in paying if they are free of charge).

Off-site improvements' services like roads, amenity planting, street lighting are pure public goods as they have all three properties.

Urban electric transport is a mixed good. On the one hand, it is impossible to restrict access to transport for everyone. On the other, a consumer has an alternative to public transport - private one. In addition, satisfaction of service consumption depletes as the number of transport services users rises (for example, discomfort of passengers because of traffic congestion). Its maintenance is carried out partly at the expense of budgetary funds (as a public good), partly costs are covered at the expense of residents in the form of a fare (as a private good).

From the list of housing and communal services regarding the mechanism of their financing in CTV,

Special attention has to be paid to public and mixed goods from the list of housing and community amenities regarding the mechanism of their funding in UTCs.

Budget expenditure for public services funding have to be provided depending on the number of settlement's residents. All other expenditure, above all development budget expenditure, should be distributed according multicriteria mechanism. This also applies to basic subsidies, educational subvention, medical subvention and other State Budget`s subventions.

To plan UTCs and their settlements development (provision of public goods, capital expenditure, level of income, provision of resources and goods, etc.), it is necessary to take into account the population size and potential changes over a period of time.
To simulate the described situation we apply the system of linear homogeneous difference equations. Let us assume that UTC comprises $n \geq 2$ settlements $D_{1}, D_{2}, \ldots ., D_{n}$ and there is the following migration between them: for all $i \neq j$ is the same part $a_{i j}$ of residents of a settlement $D_{j}$ goes to settlement $D_{i}$, and part $a_{j i}$ of residents of a settlement $D_{j}$ migrates to $D_{i}$, but part $a_{j i}$ stays in it. Let $x_{i}(t)$ be residents of settlement $D_{i}$ in $\mathrm{t}$-period. Then,

$$
x_{1}(t+1)=a_{i 1} x_{1}(t)+a_{i 2} x_{2}(t)+\ldots .+a_{i n} x_{n}(t),
$$

since for vector $x(t)=\left(x_{1}(t) ; x_{2}(t) ; \ldots ; x_{n}(t)\right)$ we obtain the system of discretized equations:

$$
x(t+1)=A x(t)
$$

were $\mathrm{A}$ is an integral matrix which elements obey these conditions:

$$
0 \leq a_{i j} \leq 1, a_{1 j}+a_{2 j}+\ldots . .+a_{n j}=1, \quad j=\overline{1, n} .
$$

Let us study $n$ equation solutions (1) $x^{1}(t), x^{2}(t), \ldots, x^{n}(t)$, determined by the next initial conditions:

$$
\begin{aligned}
& x^{1}\left(t_{0}\right)=x_{0}^{1}=\left(x_{11}^{0} ; x_{21}^{0} ; \ldots ; x_{n 1}^{0}\right), \\
& x^{2}\left(t_{0}\right)=x_{0}^{2}=\left(x_{12}^{0} ; x_{22}^{0} ; \ldots ; x_{n 2}^{0}\right), \\
& x^{n}\left(t_{0}\right)=x_{0}^{n}=\left(x_{1 n}^{0} ; x_{2 n}^{0} ; \ldots ; x_{n n}^{0}\right) .
\end{aligned}
$$

The sum of solutions $x^{1}(t), x^{2}(t), \ldots, x^{n}(t)$ of equation (1), which obey conditions (2), are called fundamental system of solutions if the determinant does not equal zero:

$$
\left|X\left(t_{0}\right)\right|=\left|\begin{array}{cccc}
x_{11}^{0} & x_{12}^{0} & \cdots & x_{1 n}^{0} \\
x_{21}^{0} & x_{22}^{0} & \cdots & x_{2 n}^{0} \\
\cdots \ldots \ldots \ldots \ldots \ldots \ldots . \\
x_{n 1}^{0} & x_{n 2}^{0} & \cdots & x_{n n}^{0}
\end{array}\right| \neq 0
$$

If $x^{1}(t), x^{2}(t), \ldots, x^{n}(t)$ is a fundamental system of solutions of equation (1), then any solution $\bar{x}(t)$ of rhis equation can be presented as:

$$
\bar{x}(t)=C_{1} x^{1}(t)+C_{2} x^{2}(t)+\ldots+C_{n} x^{n}(t),
$$

where $C_{1}, C_{2}, \ldots, C_{n}$ - constants.

Let us apply the system of linear homogeneous difference equations with fixed factors:

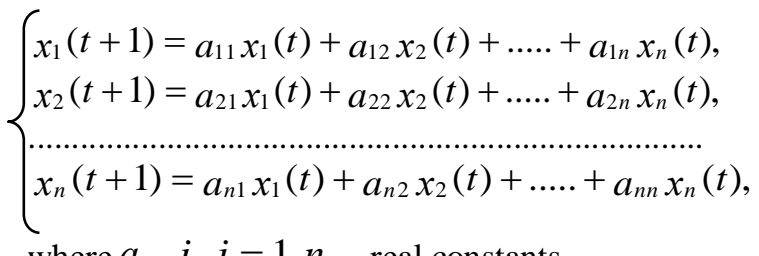


System solution (3) will be obtained in the form:

$$
x_{1}=\gamma_{1} \lambda^{t}, x_{2}=\gamma_{2} \lambda^{t}, \ldots . ., x_{n}=\gamma_{n} \lambda^{t}, \lambda \neq 0,
$$

where $\gamma_{1}, \gamma_{2}, \ldots, \gamma_{n}$ and $\gamma$ - numbers, which have to be determined.

Let us substitute expression (4) into system (3) after reduction of $\lambda^{t}$ and obtain:

$$
\left\{\begin{array}{l}
\left(a_{11}-\lambda\right) \gamma_{1}+a_{12} \gamma_{2}+\ldots+a_{1 n} \gamma_{n}=0 \\
\left(a_{21}-\lambda\right) \gamma_{1}+a_{22} \gamma_{2}+\ldots+a_{2 n} \gamma_{n}=0 \\
\cdots \ldots \ldots \ldots \ldots \ldots \ldots \ldots \ldots \ldots \ldots \ldots \ldots \ldots \ldots \ldots \ldots \ldots \ldots \ldots \ldots \ldots \ldots \ldots \ldots \ldots \ldots \ldots \ldots \ldots \ldots \ldots \ldots \ldots \ldots \ldots \ldots \ldots \ldots \ldots \ldots \ldots \ldots \ldots \ldots \ldots \ldots \ldots \ldots \\
\left(a_{n 1}-\lambda\right) \gamma_{1}+a_{n 2} \gamma_{2}+\ldots+a_{n n} \gamma_{n}=0
\end{array}\right.
$$

System (5) has zero solution if its determinant equals zero, which is necessary and sufficient:

$$
\left|\begin{array}{cccc}
a_{11}-\lambda & a_{12} & \cdots & a_{12} \\
a_{21} & a_{22}-\lambda & \cdots & a_{2 n} \\
\cdots \cdots \cdots \cdots \cdots \cdots \cdots \cdots \cdots \cdots \cdots \cdots & \cdots \cdots \cdots \cdots \cdots \cdots \cdots \\
a_{n 1} & a_{n 2} & \cdots & a_{n n}-\lambda
\end{array}\right|=0 .
$$

Equation (6) is called characteristical for system (3).

To plan UTC future development based on its residents distribution between settlements it is necessary to study vector behavior $x(t)$ when $t \rightarrow \infty$. To do this, we need to look for a complementary solution to the system (1).

Let us consider the case when UTC comprises three settlements, that is $n=3$.

We assume that

$a_{21}=\alpha_{1}, \quad a_{31}=\alpha_{2}, \quad a_{12}=\beta_{1}, \quad a_{32}=\beta_{2}$,

$a_{13}=\beta_{1}, \quad a_{23}=\beta_{3}$.

Then matrix A will be:

$$
\mathrm{A}=\left(\begin{array}{ccc}
1-\alpha_{1}-\alpha_{2} & \beta_{1} & \beta_{1} \\
\alpha_{1} & 1-\beta-\beta_{2} & \beta_{3} \\
\alpha_{2} & \beta_{2} & 1-\beta_{1}-\beta_{3}
\end{array}\right) .
$$

We obtain for system (1) with the matrix A complementary solution.

Characteristical numbers of matrix A are found from the equation

$$
\left|\begin{array}{ccc}
1-\alpha_{1}-\alpha_{2}-\lambda & \beta_{1} & \beta_{1} \\
\alpha_{1} & 1-\beta_{1}-\beta_{2}-\lambda & \beta_{3} \\
\alpha_{2} & \beta_{2} & 1-\beta_{1}-\beta_{3}-\lambda
\end{array}\right|=0,
$$

or

$$
\begin{aligned}
& \left(1-\lambda-\alpha_{1}-\alpha_{2}\right)\left(1-\lambda-\beta_{1}-\beta_{2}\right)\left(1-\lambda-\beta_{1}-\beta_{3}\right)+ \\
& +\alpha_{1} \beta_{2} \beta_{1}+\beta_{1} \beta_{3} \alpha_{2}-\left(1-\lambda-\beta_{1}-\beta_{2}\right) \alpha_{2} \beta_{1}- \\
& -\left(1-\lambda-\alpha_{1}-\alpha_{2}\right) \beta_{2} \beta_{3}-\left(1-\lambda-\beta_{1}-\beta_{3}\right) \alpha_{1} \beta_{1}=0 .
\end{aligned}
$$

The last equation can be written as

$$
\begin{aligned}
& (1-\lambda)^{3}-(1-\lambda)^{2}-\left(\alpha_{1}+\alpha_{2}+2 \beta_{1}+\beta_{2}+\beta_{3}\right)+ \\
& +(1-\lambda)\left(\left(\alpha_{1}+\alpha_{2}\right)\left(\beta_{1}+\beta_{2}\right)+\left(\alpha_{1}+\alpha_{2}\right)\left(\beta_{1}+\beta_{3}\right)+\right) \\
& +\left(\beta_{1}+\beta_{2}\right)\left(\beta_{1}+\beta_{3}\right)-\alpha_{2} \beta_{1}-\beta_{2} \beta_{3}-\alpha_{1} \beta_{1}=0 .
\end{aligned}
$$

The we obtain $\lambda_{1}=1, \quad a$ the other two roots are from equation

$$
\begin{aligned}
& (\lambda-1)^{2}+(\lambda-1)\left(\alpha_{1}+\alpha+2 \beta_{1}+\beta_{2}+\beta_{3}\right)+ \\
& +\left(\alpha_{1}+\alpha_{2}+\beta_{1}\right)\left(\beta_{1}+\beta_{2}^{2}+\beta_{3}\right)=0
\end{aligned}
$$

These roots are $\lambda=1-\alpha_{1}-\alpha_{2}-\beta_{1} \quad \mathrm{i}$ $\lambda_{3}=1-\beta_{1}-\beta_{2}-\beta_{3}$. We build system for each root (5). When $\lambda_{1}=1$ it is

$$
\left\{\begin{array}{l}
\left(-\alpha_{1}-\alpha_{2}\right) \gamma_{1}+\beta_{1} \gamma_{2}+\beta_{1} \gamma_{3}=0 \\
\alpha_{1} \gamma_{1}-\left(\beta_{1}+\beta_{2}\right) \gamma_{2}+\beta_{3} \gamma_{3}=0 \\
\alpha_{2} \gamma_{1}+\beta_{2} \gamma_{2}-\left(\beta_{1}+\beta_{3}\right) \gamma_{3}=0
\end{array}\right.
$$

Subtracting from the second equation of the system multiplied by $\alpha_{2}$, third equation, multiplied by $\alpha_{1}$, we obtain:

$$
\left(-\alpha_{2} \beta_{1}-\alpha_{2} \beta_{2}-\alpha_{1} \beta_{2}\right) \gamma_{2}+\left(\alpha_{2} \beta_{3}+\alpha_{1} \beta_{3}+\alpha_{1} \beta_{1}\right) \gamma_{3}=0 \text {. }
$$

We think that $\gamma_{3}=\alpha_{2} \beta_{1}+\alpha_{2} \beta_{2}+\alpha_{1} \beta_{2}$,we have: $\gamma_{2}=\alpha_{2} \beta_{3}+\alpha_{1} \beta_{3}+\alpha_{1} \beta_{1}$. We substitute these values $\gamma_{2}$ and $\gamma_{3}$ to the first equation of the system and obtain: $\gamma_{1}=\beta_{1} \beta_{2}+\beta_{1}^{2}+\beta_{1} \beta_{3}$.

Substituting system (5) $\lambda_{2}=1-\alpha_{1}-\alpha_{2}-\beta_{1}$, we have:

$$
\left\{\begin{array}{l}
\beta_{1} \gamma_{1}+\beta_{1} \gamma_{2}+\beta_{1} \gamma_{3}=0, \\
\alpha_{1} \gamma_{1}+\left(\alpha_{1}+\alpha_{2}-\beta_{2}\right) \gamma_{2}+\beta_{3} \gamma_{3}=0, \\
\alpha_{2} \gamma_{1}+\beta_{2} \gamma_{2}+\left(\alpha_{1}+\alpha_{2}-\beta_{3}\right) \gamma_{3}=0 .
\end{array}\right.
$$

Multiplying the second equation of the system by $\alpha_{2}$, and the third by $\alpha_{1}$ and subtracting the obtained equation, we have:

$$
\begin{aligned}
& \left(-\alpha_{1} \beta_{2}+\alpha_{1} \alpha_{2}+\alpha_{2}^{2}-\beta_{2} \alpha_{2}\right) \gamma_{2}+ \\
& +\left(\beta_{3} \alpha_{1}-\alpha_{1}^{2}-\alpha_{1} \alpha_{2}+\beta_{3} \alpha_{2}\right) \lambda_{3}=0
\end{aligned}
$$

then if $\gamma_{2}=\alpha_{1}^{2}-\alpha_{1} \beta_{3}+\alpha_{1} \alpha_{2}-\alpha_{2} \beta_{3}$, we obtain:

$$
\gamma_{3}=\alpha_{1} \alpha_{2}-\alpha_{1} \beta_{2}+\alpha_{2}^{2}-\beta_{2} \alpha_{2} \text {. }
$$

Then

$$
\gamma_{1}=\left(\alpha_{1}+\alpha_{2}\right)\left(\beta_{3}+\beta_{2}-\alpha_{1}-\alpha_{2}\right) \text {. }
$$

For $\lambda_{3}=1-\beta_{1}-\beta_{2}-\beta_{3}$ we have:

$$
\left\{\begin{array}{l}
\left(-\alpha_{1}-\alpha_{2}+\beta_{1}+\beta_{2}+\beta_{3}\right) \gamma_{1}+\beta_{1} \gamma_{2}+\beta_{1} \gamma_{3}=0 . \\
\alpha_{1} \gamma_{1}+\beta_{3} \gamma_{2}+\beta_{3} \gamma_{3}=0 . \\
\alpha_{2} \gamma_{1}+\beta_{2} \gamma_{2}+\beta_{2} \gamma_{2}=0 .
\end{array}\right.
$$

After multiplication of the second equation by $\alpha_{2}$, and the third by $\alpha_{1}$ and subtracting we obtain: $\left(\beta_{3} \alpha_{2}-\alpha_{1} \beta_{2}\right) \gamma_{2}+\left(\alpha_{2} \beta_{3}-\alpha_{1} \beta_{2}\right) \gamma_{3}=0$.

We consider that $\gamma_{2}=\alpha_{2} \beta_{3}-\alpha_{1} \beta_{2}$, then we have: 


$$
\gamma_{3}=\alpha_{1} \beta_{2}-\beta_{3} \alpha_{2}
$$

Obtain from the first equation: $\gamma_{1}=0$

The fundamental system of solution is presented as: for $\lambda_{1}=1$

$$
\left\{\begin{array}{l}
x_{11}=\beta_{1} \beta_{2}+\beta_{1}^{2}+\beta_{1} \beta_{3} \\
x_{21}=\alpha_{2} \beta_{3}+\alpha_{1} \beta_{3}+\alpha_{1} \beta_{1} \\
x_{31}=\alpha_{2} \beta_{1}+\alpha_{2} \beta_{2}+\alpha_{1} \beta_{2}
\end{array}\right.
$$

for $\lambda_{2}=1-\alpha_{1}-\alpha_{2}-\beta_{1}$

$$
\left\{\begin{array}{l}
x_{12}=\left(\alpha_{1}+\alpha_{2}\right)\left(\beta_{3}+\beta_{2}-\alpha_{1}-\alpha_{2}\right)\left(1-\alpha_{1}-\alpha_{2}-\beta_{1}\right)^{t} \\
x_{22}=\left(\alpha_{1}^{2}-\alpha_{1} \beta_{3}+\alpha_{1} \alpha_{2}-\alpha_{2} \beta_{3}\right)\left(1-\alpha_{1}-\alpha_{2}-\beta_{1}\right)^{t} \\
x_{32}=\left(\alpha_{1} \alpha_{2}-\alpha_{1} \beta_{2}+\alpha_{2}^{2}-\beta_{2} \alpha_{2}\right)\left(1-\alpha_{1}-\alpha_{2}-\beta_{1}\right)^{t}
\end{array}\right.
$$

for $\lambda_{3}=1-\beta_{1}-\beta_{2}-\beta_{3}$

$$
\begin{gathered}
x_{13}=0, \\
x_{23}=\left(\alpha_{2} \beta_{3}-\alpha_{1} \beta_{2}\right)\left(1-\beta_{1}-\beta_{2}-\beta_{3}\right)^{t}, \\
x_{33}=\left(\alpha_{1} \beta_{2}-\beta_{3} \alpha_{2}\right)\left(1-\beta_{1}-\beta_{2}-\beta_{3}\right)^{t} .
\end{gathered}
$$

Complementary system solution is:

$$
\begin{aligned}
& x_{1}=C_{1}\left(\beta_{1} \beta_{2}+\beta_{1}^{2}+\beta_{1} \beta_{3}\right)+ \\
& +C_{2}\left(\alpha_{1}+\alpha_{2}\right)\left(\beta_{3}+\beta_{2}-\alpha_{1}-\alpha_{2}\right)\left(1-\alpha_{1}-\alpha_{2}-\beta_{1}\right)^{t}, \\
& x_{2}=C_{1}\left(\alpha_{2} \beta_{3}+\alpha_{1} \beta_{3}+\alpha_{1} \beta_{1}\right)+ \\
& +C_{2}\left(\alpha_{1}^{2}-\alpha_{1} \beta_{3}+\alpha_{1} \alpha_{2}-\alpha_{2} \beta_{3}\right)^{t}+ \\
& +C_{3}\left(\alpha_{2} \beta_{3}-\alpha_{1} \beta_{2}\right)\left(1-\beta_{1}-\beta_{2}-\beta_{3}\right)^{t} . \\
& x_{3}=C_{1}\left(\alpha_{2} \beta_{1}+\alpha_{2} \beta_{2}+\alpha_{1} \beta_{2}\right)+ \\
& +C_{2}\left(\alpha_{1} \alpha_{2}-\alpha_{1} \beta_{2}+\alpha_{2}^{2}-\beta_{2} \alpha_{2}\right)\left(1-\alpha_{1}-\alpha_{2}-\beta_{1}\right)^{t}+ \\
& +C_{3}\left(\alpha_{1} \beta_{2}-\beta_{3} \alpha_{2}\right)\left(1-\beta_{1}-\beta_{2}-\beta_{3}\right)^{t}
\end{aligned}
$$

Therefore, based on these equations, it is possible to calculate population size at certain time intervals (the beginning $\mathrm{t}=0$ ). Taking into account the expected (planned) changes in each settlement's population size in UTC territory, it is possible to distribute planned expenditure for providing public goods.

This allows to form the financial revenue distribution models that make up UTCs budgets and to take into account in territorial development strategies and projects such components as: budget revenue dynamics, territorial peculiarities and development determinants, employment rates and migration capacity.

The decentralization process has intensely started since 2015. During the initial stage separate territorial communities were organized, which started the integration process to form UTCs during 2016-2017. Unfortunately, the deceleration of the UTCs formation started in 2017 due to the inefficient regulation of UTCs consolidation. Intensification of decentralization process started only in 2018. It is found impossible to illustrate practical facets of the model in retrospect, which stems from: population size data is out-of-date as the last population census was held in 2001 n Ukraine; official statistics does not take into account circular (short-term) migration inside one country, its regions and certain settlements; population registration in
Ukraine includes not the residence but the registration place, which sometimes do not coincide. Total public goods cannot be accurately estimated as actual consumption data is approximate, expert one. As the first stage of reforms is finished by the end of 2019 , the purpose of our study was to build economic and mathematical model of financial resource management for public goods provision during the next phase of reforms. By now the decision to improve decentralization reform frame has been made. The accent is transferred from basic to sub-regional level aimed at UTCs and regions consolidation, considerable reduction in their number. The model proposed by us was built just for the second phase of reforms, which have to be intensified in Ukraine by 2020. Thus, the main tasks of UTCs formation in the nearest future are setting of ration measures and sustainability of territories development. To do this we propose economic and mathematical modelling of UTC formation in certain territorial measures.

Assume that in system (1) matrix A is

$$
A=\left(\begin{array}{ccc}
0,4 & 0,1 & 0,1 \\
0,4 & 0,8 & 0,3 \\
0,2 & 0,1 & 0,6
\end{array}\right)
$$

Let us find the law of population distribution in three settlements for this case.

Characteristical equation is

$$
\left|\begin{array}{ccc}
0,4-\lambda & 0,1 & 0,1 \\
0,4 & 0,8-\lambda & 0,3 \\
0,2 & 0,1 & 0,6-\lambda
\end{array}\right|=0
$$

or $\lambda^{3}-1,8 \lambda+0,95 \lambda-0,15=0$.

Its roots are $\lambda_{1}=1, \lambda_{2}=0,3, \lambda_{3}=0,5$.

For $\lambda_{1}=1$ we have the system (5):

$$
\left\{\begin{array}{c}
-0,6 \gamma_{1}+0,1 \gamma_{2}+0,1 \gamma_{3}=0 \\
0,4 \gamma_{1}-0,2 \gamma_{2}+0,3 \gamma_{3}=0 \\
0,2 \gamma_{1}+0,1 \gamma_{2}-0,4 \gamma_{3}=0
\end{array}\right.
$$

Then $\gamma_{1}=0,5, \quad \gamma_{2}=2,2, \quad \gamma_{3}=0,8$.

For $\lambda_{2}=0,3$ from system

$$
\left\{\begin{array}{l}
0,1 \gamma_{1}+0,1 \gamma_{2}+0,1 \gamma_{3}=0 \\
0,4 \gamma_{1}+0,5 \gamma_{2}+0,3 \gamma_{3}=0 \\
0,2 \gamma_{1}+0,1 \gamma_{2}+0,3 \gamma_{3}=0
\end{array}\right.
$$

obtain: $\gamma_{1}=-2, \quad \gamma_{2}=1, \quad \gamma_{3}=1$.

System

$$
\left\{\begin{array}{c}
-0,1 \gamma_{1}+0,1 \gamma_{2}+0,1 \gamma_{3}=0 \\
0,4 \gamma_{1}+0,3 \gamma_{2}+0,3 \gamma_{3}=0 \\
0,2 \gamma_{1}+0,1 \gamma_{2}+0,1 \gamma_{3}=0
\end{array}\right.
$$

If $\lambda_{3}=0,5$, we obtain the following solution: $\gamma_{1}=0, \gamma_{2}=1, \gamma_{3}=-1$.

Fundamental system of solution is the following: 
For $\lambda_{1}=1$

$$
\chi_{11}=0,5, \chi_{21}=2,2, \chi_{31}=0,8 ;
$$

for $\lambda_{2}=0,3$

$$
\chi_{12}=-2(0,3)^{t}, \chi_{22}=(0,3)^{t}, \chi_{32}=(0,3)^{t} \text {; }
$$

for $\lambda_{3}=0,5$

$$
\chi_{13}=0, \chi_{23}=(0,5)^{t}, \chi_{33}=-(0,5)^{t} \text {. }
$$

Thus, we obtain:

$$
\begin{gathered}
\chi_{1}(t)=0,5 C_{1}-2 C_{2}(0,3)^{t}, \\
\chi_{2}(t)=2,2 C_{1}+C_{2}(0,3)^{t}+C_{3}(0,5)^{t}, \\
\chi_{3}(t)=0,8 C_{1}+C_{2}(0,3)^{t}-C_{3}(0,5)^{t} .
\end{gathered}
$$

This is complementary solution of this model.

Thus the obtained equations describe the dynamics of the population size changes in three settlements of UTCs and can be used for UTCs financial resource distribution planning aimed at certain settlements development.

\section{CONClUSIONS}

This paper analyzes current system of united territorial communities` expenditure, which includes financing of education, culture, health care, social safety net, housing and community amenities, infrastructure development. It has been shown that current united territorial communities regulatory framework lacks effective guarantees of an optimal, balanced budget distribution between the settlements - UTC members. The causes of distribution problems have been identified, namely: UTCs include settlements with different population size and per capita income levels, and there is volatility of population caused by migration processes of different duration. Therefore, the need to build mechanism for effective UTCs budget distribution based on the real communities` needs and capabilities has been demonstrated. International experience does not have effective mechanisms for expenditure distribution for budgets, especially when we take into account local Ukrainian context. UTCs can be dramatically different in terms of their capability and capacity, even in administrative area. Therefore, community financial resource distribution should be as efficient as possible and free from shortsighted decisions.

It has been proved in the study that expenditure differentiation based on a multi-criteria principle should be carried out primarily when funding housing and community amenities provision related to public and mixed goods.

It has been shown that UTCs' and settlements development planning (provision of public goods, capital expenditure, level of income, provision of resources and benefits, etc.), should be carried out taking into account their population size and potential changes during certain period. A system of linear homogeneous difference equations has been applied to model the described situation.

It has been suggested: to balance budget revenue and expenditure within the framework of sustainable territorial development, it is advisable to calculate the population size during certain periods. These periods should take into account the expected changes in each settlement's population size inside UTC's territory. The planned expenditure distribution should be based on the provision of public goods to ensure social equality and harmonious development. The amount of social goods funding should be assessed based on proposed economic and mathematical approaches, which can be part of the information and analytical support of local government and self-government.

\section{REFERENCES}

[1] Decree of the President of Ukraine «On the Strategy of Sustainable Development» Ukraine-2020» (from January 12, 2015, № 5/2015). URL: http://zakon5.rada.gov.ua/laws/show/5/2015. [in Ukrainian].

[2] H. Wollmann, "Reorganizing Local Government: Between Territorial Consolidation and Two-tier Intermunicipality", HKJU-CCPA, vol. 11(3), p. 681-706, 2011.

[3] C. Andre, and C. Garcia, "Local Public Finances and Municipal Reform in Finland, OECD Economics Department Working Papers, No 1121, 2014. OECD Publishing. URL: http:dx.doi.org/10.1787/5jz2qt0zj024-en

[4] A. Feltensteina, and S. Iwata, "Decentralization and macroeconomic performance in China: regional autonomy has its costs", Jornal of Development Economics, No 76, p. 481-501, 2015.

[5] L. Rudenko, and S. Lisovsky, E. Maruniak, "Challenges and threats of spatial development of Ukraine on the way to European integration”, Ukrainian geography journal, №1, p.124-136. [in Ukrainian].

[6] Territorial community as a base part of the administrative territorial device of Ukraine: problems and prospects of reforming. The analytical report. Kyiv.: NISI, 2016. [in Ukrainian].

[7] O.V. Batanov, A territorial community - primary subject of municipal authority in Ukraine: concept and attribute. URL: http://www.cvk.gov.ua/visnyk/pdf/2008_2/visnik_st_13.pdf. (date of treatment 04.02.2018) [in Ukrainian].

[8] L.A. Murkovich, "Territorial community as the subject of local selfmanagement in Ukraine: theoretical aspects". URL: http://www.dbuapa.dp.ua/vidavnictvo/2010/2010_02\%285\%29/10mli uta.pdf. (date of treatment 04.02.2018). [in Ukrainian].

[9] L. Horoshkova, and V.P. Volkov, I.O. Karbivnychyi, R.O. Karbivnychyi, I.A. Horbova, Conditions of the no-loss functioning of territorial formation. Belostok: Belostok, 2018.

[10] L. Horoshkova, and V. Volkov, L. Kapranova, A. Komelina, "The Reverse Subsidy`s Impact of United Territorial Community`s Budget Generations", International Journal of Engineering \& Technology, № 7(4.8), p. 539-543, 2018.

[11] L.A. Horoshkova, and V.P. Volkov, Ie.V. Khlobistov, V.V. Kutyk, "Prognostic models of financial regulation of budgets of territorial communities", University Economic Bulletin of PereyaslavKhmelnytsky State Pedagogical University, No. 42, p. 179-190, 2019. [in Ukrainian].

[12] On approval of the Methodology for the formation of capable territorial communities: Resolution of the Cabinet of Ministers of Ukraine dated April 8, 2015, No. 214.). URL: http://zakon2.rada.gov.u. [in Ukrainian]. 